\title{
Effect of Ventilation on Mechanical Properties and Pressure-Flow Relationships of Immature Airways
}

\author{
RAYMOND B. PENN, MARLA R. WOLFSON, AND THOMAS H. SHAFFER \\ Departments of Physiology and Pediatrics, Temple University School of Medicine, Philadelphia, Pennsylvania
} 19140

\begin{abstract}
Ventilation of immature airways has been shown to result in pressure-induced deformation and alteration of mechanical properties. These changes in mechanical properties may alter the effect of compressive pressures on pressure-flow relationships. To test this hypothesis, unventilated (Group I, $n=8$ ) and ventilated (group II, $n=8$; mean pressures of 8-12 $\mathrm{cm} \mathrm{H}_{2} \mathrm{O}$ for $2 \mathrm{~h}$ duration) tracheal segments were excised from preterm lambs approximately 118 days gestation and mounted in a Krebsfilled chamber for determination of compliances and pressure-flow relationships. Compliance data were obtained for both the inflation loop (inflation compliance) and the collapsing loop (collapsing compliance) of the pressure-volume curve for each segment. Flow ( $\dot{V}=2-10 \mathrm{liter} / \mathrm{min}$.) was introduced through the lumen of each segment at different chamber pressures $(\mathrm{Pc}=5-30 \mathrm{~mm} \mathrm{Hg})$. Driving pressure (Pd) was recorded for each $\dot{V}$ and Pc. Airway resistance (R) was calculated as $\mathrm{Pd} / \dot{\boldsymbol{V}}$. Group II had significantly greater $(p<0.005)$ radii than Group $I$, suggesting ventilation-induced deformation. Group II had significantly lower $(p<0.05)$ inflation compliance but significantly greater $(p<0.05)$ collapsing compliance than group I. Two-factor analysis of variance demonstrated significantly greater $(p<0.05) \mathrm{R}$ in group II at each value of $\dot{V}$ and each Pc. These data may help to explain the flow limitation and gas-trapping observed in preterm infants who have been mechanically ventilated. (Pediatr Res 23:519-524, 1988)
\end{abstract}

\section{Abbreviations}

P-V, pressure-volume

ANOVA, analysis of variance

EPP, equal pressure point

FLS, flow-limiting segment

MEF, maximum expiratory flow

Pressure-flow relationships of airways subjected to compressive forces have been shown to be determined in part by airway mechanical properties. Specifically, the compliance of the airway as determined by the collapsing loop of the P-V curve will define the degree of airway compression or narrowing associated with negative transmural pressures. Airway compression results in increased resistance to airflow. This relationship between airway

Received September 14, 1987; accepted January 14, 1988.

Correspondence and reprints R. B. Penn, c/o T. H. Shaffer, Department of Physiology, Temple University School of Medicine, 3420 N. Broad Street, Philadelphia, PA 19140.

Supported by NIH Grant NHLBI HL 32031 compliance, airway compression, and resistance to airflow has been studied extensively in adult airways (1-3), to a lesser degree in newborn airways (4), and there is no research with respect to the premature airway.

Prolonged mechanical ventilation has little effect on adult airways but has been shown to effect the dimensions (5-8) and mechanical properties $(5,9)$ of preterm and newborn airways. However, analysis of these mechanical properties in preterm and newborn airways extended only to the compliance as determined by the inflation loop of the P-V curve. This provided no insight into airway rigidity under compression. It is therefore unclear how mechanical ventilation affects the immature airway's ability to withstand compressive collapse and thereby influences pressure-flow relationships.

This study was designed to evaluate the effects of ventilation on the mechanical properties and pressure-flow relationships of preterm lamb tracheae. Differences in compliances defined by both the inflation and collapsing loops of the P-V curve of ventilated and unventilated tracheal segments were examined. Resistance to airflow over a physiological range of flows and compressive pressures was also determined in both groups, and intergroup differences were associated with observed differences in compliances. This study may help to explain how ventilation influences the ability of the premature airway to withstand compressive collapse, and further aid in the understanding of flow limitation and gas-trapping observed in infants who have been mechanically ventilated.

\section{METHODS}

The apparatus used in these experiments (Fig. 1) is an adaptation of the model developed by Coburn et al. (3). It consists of a $200-\mathrm{ml}$ cylindrical plastic chamber $(A)$ with one permanent $(B)$ and one removable $(C)$ end plate. The permanent end plate supported in its center the barrel of a $10-\mathrm{ml}$ syringe with its respective plunger which was adapted to serve as a sliding mount $(D)$. The center of the removable endplate supported one arm of a t-connector that functioned as a fixed mount $(E)$. The other arm of the t-connector perpendicular to the fixed mount $(F)$ was connected to pressure transducer $(G)$ that measured inlet or driving pressure $\mathrm{Pd}$. The remaining arm of the $\mathrm{t}$-connector was connected to the airflow system by a piece of $1 / 8$ inch plastic tubing containing an injection port $(H)$.

The airflow system consisted of a pressurized air source $(n)$ with a filter $(J)$, a rotometer $(K)$ for regulating air flow, and a humidifier $(L)$.

The chamber was supplied with $37^{\circ} \mathrm{C}$ Krebs-buffer solution by a pump-reservoir system. One-eighth inch plastic tubing linked the outflow port $(M)$ of the chamber to a pressure transducer $(N)$, which measured chamber pressure $\mathrm{Pc}$, in series with a reservoir $(O)$. A gaseous mixture of $95 \% \mathrm{O}_{2}-5 \% \mathrm{CO}_{2}$ was 


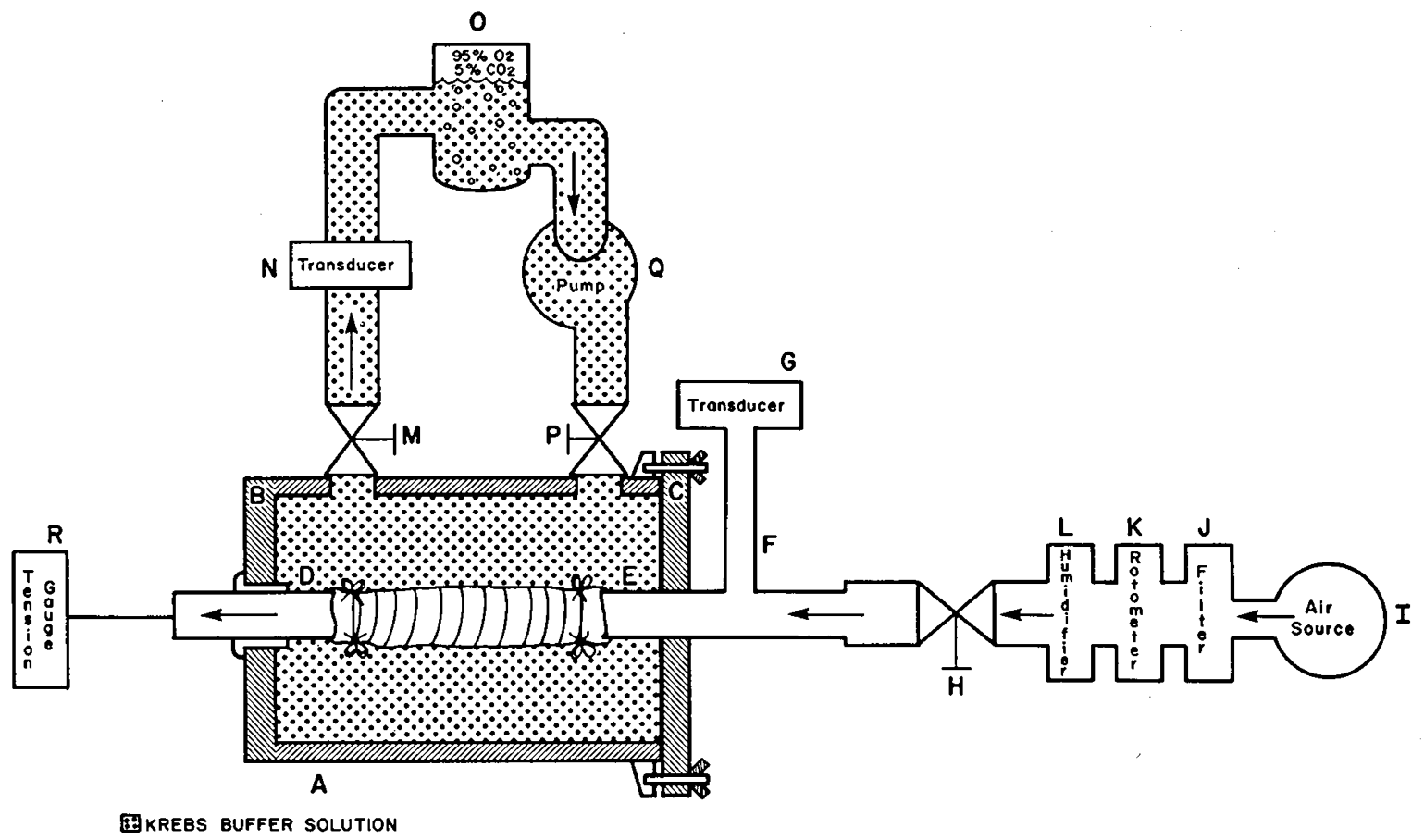

Fig. 1. Schematic diagram of apparatus used to determine compliance and pressure-flow relationships of tracheal segments. $A$, plastic chamber; $B$, permanent end plate; $C$, removable end plate; $D$, sliding mount; $E$, fixed mount; $F$, t-connector arm to transducer; $G$, pressure transducer measuring driving pressure; $H$, injection port; $I$, air source; $J$, filter; $K$, rotometer; $L$, humidifier; $M$, outflow port; $N$, pressure transducer measuring chamber pressure; $O$, reservoir; $P$, inflow port; $Q$, peristaltic pump; $R$, tension gauge.

bubbled into the reservoir. $\mathrm{pO}_{2}$ was therefore maintained above $550 \mathrm{~mm} \mathrm{Hg} ; \mathrm{pH}$ was controlled at $7.40 \pm 0.03$. The temperature of the solution was maintained at $37^{\circ} \mathrm{C}$ by a water-filled heating jacket around the reservoir. The solution was returned to the inflow port $(P)$ of the chamber by an intervening peristaltic pump $(Q)$. The inflow and outflow ports of the chamber were modified for injection/withdrawal with stopcocks, so that $\mathrm{Pc}$ might be varied. All pressure transducers were connected to an Electronics for Medicine VR-6 Simultrace Recorder, and pressures were monitored throughout the entire experiment.

Tracheal segments from two groups of preterm lambs 114121 days gestation (extreme prematurity) were excised from a region of the trachea from which the cephalic border was at least $3 \mathrm{~mm}$ below the cricoid cartilage and caudal border at least 20 $\mathrm{mm}$ above the carina and immediately placed in physiological Krebs-buffer solution. All lambs had been ventilated (mean pressures 8-12 $\mathrm{cm} \mathrm{H} \mathrm{H}_{2} \mathrm{O}$; peak pressures not exceeding $20 \mathrm{~cm}$ $\mathrm{H}_{2} \mathrm{O}$ inspiratory phase, $-5 \mathrm{~cm} \mathrm{H}_{2} \mathrm{O}$ expiratory phase, mean duration $2 \mathrm{~h}$ ) with oxygenated fluorocarbon, which is presently the only effective means to ventilate lambs of this age and maintain physiological gas exchange and acid-base conditions (10) (see "Discussion"). Excised segments were determined to be viable by trachealis muscle bath studies (11) performed in concurrence with the present study. Segments were divided into two groups. Group I consisted of segments $(n=8, r=3.20 \pm 0.5$ $\mathrm{mm}$ SEM, $l=22.95 \pm 0.54 \mathrm{~mm}$ ) excised from a region of the trachea never exposed to ventilatory pressure. Group II consisted of segments $(n=8, r=3.42 \pm 0.03 \mathrm{~mm}, l=22.58 \pm 0.46 \mathrm{~mm})$ from the same region but exposed to fluorocarbon ventilation. By introducing the tracheostomy tube into the caudal trachea of one group of animals an unventilated segment (group I) of sufficient length was obtained; introducing the tube more cephalic in the other group of animals provided a more suitable ventilated segment (group II).

A small ring of tissue was clipped from the end of each excised tracheal segment. Measurements of this ring with a max-Cal electronic digital caliper were used to determine tracheal circumference and radius.
After removing the external fascia, the tracheal segment was tied to the sliding and fixed mount (outside of the chamber) with $1 / 8$ inch umbilical tape. The plunger (sliding mount) was then passed through the barrel (end plate $B$ ) while the removable end plate (fixed mount) was secured to the chamber. The chamber was filled with the oxygenated Krebs-buffer solution. Pressure transducer $N$ was placed at the level of the trachea and balanced to ambient pressure. Pressure transducer $N$ was then closed off to the reservoir and the chamber inflow port was closed to the pump and opened to atmosphere.

The sliding mount was connected to a tension gauge $(R)$ and the trachea/mount was stretched back until a finite longitudinal tension was recorded. This tension was slowly released until tracheal tension was zero once again. At this point the sliding mount was clamped and tracheal length was fixed throughout the entire experiment. Tracheal segment length was measured as the distance between the ties securing the segment after the sliding mount was clamped.

$P$-V relationships. The distal end of the plunger (sliding mount) was plugged and the plastic tubing linking the humidifier to the t-connector was clamped on the humidifier side of injection port $H$, effecting a closed space containing the lumen of the mounted trachea. A micropipette held at tracheal level was connected to the inflow injection port $P$ of the chamber. Pressure data for the inflation P-V loop were obtained by injection of air into injection port $H$ sufficient to sequentially raise the pressure within the closed space to $5,10,20$, and $30 \mathrm{~mm} \mathrm{Hg}$ (referenced to atmosphere), and then withdrawal at the same pressure increments until atmospheric pressure was once again obtained. The change in tracheal volume was equated to the volume displacement of solution into the micropipette. The compliance of the chamber as well as the compliance of the closed space without a mounted trachea were both sufficiently small to produce negligible errors in volume change determination.

Air was then withdrawn from the closed space to produce negative transmural pressures of $-5,-10,-20$, and $-30 \mathrm{~mm}$ $\mathrm{Hg}$ within the closed space and then reinjected in the same pressure increments in order to obtain data for the collapsing P- 
$\mathrm{V}$ loop. After each P-V determination, new solution was circulated into the chamber in order to ensure tissue viability.

Pressure-flow relationships. After P-V data were recorded, the distal end of the plunger (sliding mount) was unplugged, the clamp was removed from the plastic tubing, and the micropipette was removed. The inflow port was then closed to atmosphere and sufficient volume was injected into the chamber to raise $\mathrm{Pc}$ to $5 \mathrm{~mm} \mathrm{Hg}$. Flow was introduced into the trachea at values of 2, 4, 5, 7.5, and 10 liters/min and Pd was recorded for each respective flow. Increases in Pc caused by increasing flow were quickly corrected by withdrawing the appropriate amount of solution from the chamber. The procedure was repeated for a Pc of 10,20 , and $30 \mathrm{~mm} \mathrm{Hg}$.

Results from P-V and pressure-flow studies were found to be reproducible after the tissue was allowed sufficient time to equilibrate.

Data reduction and analysis. Tracheal radius, as determined by ring measurements described above, and tracheal length were used to calculate tracheal volume, under the assumption that the trachea was a cylinder. This assumption has been defended in a previous report (12).

$\mathrm{P}-\mathrm{V}$ data for ventilated and unventilated segments were plotted as the change in tracheal volume normalized to resting volume $\Delta \mathrm{V} /$ Vo versus transmural pressure Ptm. Points for determination of inflation ( $\mathrm{Si}$ ) and collapsing slopes (Sc) (compliance) were taken from the descending limb of the inflation loop (from Ptm +10 to $0 \mathrm{~mm} \mathrm{Hg}$ ) and the ascending limb of the collapsing loop (Ptm -10 to $0 \mathrm{~mm} \mathrm{Hg}$ ), respectively. Inflation and collapsing slopes for each trachea were obtained from the best-fit line using these points.

Airway resistance was calculated as driving pressure divided by flow. Resistance to airflow of the mounting apparatus ranged from $0.002 \mathrm{~mm} \mathrm{Hg} / \mathrm{liter} / \mathrm{min}$ for 2 liter/min to $0.006 \mathrm{~mm} \mathrm{Hg} /$ liter $/ \mathrm{min}$ for $10 \mathrm{liter} / \mathrm{min}$. Flow as a function of driving pressure as well as airway resistance as a function of flow were plotted using mean data from both group I and group II at each Pc.

Groups I and II were matched for gestational age, animal body weight, and length of the mounted segment. Intergroup differences in circumference, radius, inflation slope $\mathrm{Si}$ (inflation compliance), and collapsing slope Sc (collapsing compliance) were analyzed for significance using the Student's $t$ test for independent samples. Two-factor ANOVA split-plot design was used to compare airway resistance (group I versus II) at each individual flow and each individual Pc.

\section{RESULTS}

Dimensions for both group I and group II tracheal segments are presented in Table 1 . Mean tracheal circumference and radius were significantly $(p<0.005)$ higher in the ventilated group.

Typical P-V relationships of an unventilated and ventilated segment are represented in Figure 2. P-V data for points between +10 to $0 \mathrm{~mm} \mathrm{Hg}$ and -10 to $0 \mathrm{~mm} \mathrm{Hg} \mathrm{Ptm} \mathrm{were} \mathrm{linear} \mathrm{for} \mathrm{all}$ segments. Comparison of the slopes of these lines revealed significantly lower $(p<0.05)$ compliance in the ventilated group with inflation, but significantly greater compliance in the same group with collapse (Table 2).

The pressure-flow relationships at all compressive pressures for both ventilated and unventilated groups are graphically depicted in Figure 3. The independent variable flow is plotted on the ordinate in order to produce the conventional pressure-flow curve. In both groups, Pd increased nonlinearly with increasing flow at all Pc. Driving pressure also increased with increasing Pc at any given flow value. In addition, the ventilated group required a greater $\mathrm{Pd}$ to produce the same flow at any given $\mathrm{Pc}$, represented by a shift to the right of the pressure-flow line.

Figure 4 depicts calculated airway resistance as a function of flow at $\mathrm{Pc}$ of 10,20 , and $30 \mathrm{~mm} \mathrm{Hg}$ (data for $5 \mathrm{~mm} \mathrm{Hg}$ was omitted for graph clarity). Resistance was shown to increase with decreasing flow in all cases. Two-factor ANOVA demonstrated
Table 1. Dimensions of group I (unventilated) and group II (ventilated) tracheal segments*

\begin{tabular}{ccccccc}
\hline Experiment & $\begin{array}{c}\text { GA } \\
(\text { days })\end{array}$ & $\begin{array}{c}\text { Wt } \\
(\mathrm{kg})\end{array}$ & $\begin{array}{c}\text { Circ } \\
(\mathrm{mm})\end{array}$ & $\begin{array}{c}\mathrm{Rad} \\
(\mathrm{mm})\end{array}$ & $\begin{array}{c}\mathrm{L} \\
(\mathrm{mm})\end{array}$ & $\begin{array}{c}\text { Vol } \\
(\mathrm{ml})\end{array}$ \\
\hline Group I & & & & & & \\
1 & 121 & 2.01 & 19.1 & 3.04 & 23.5 & 0.682 \\
2 & 119 & 1.65 & 20.6 & 3.28 & 24.1 & 0.815 \\
3 & 120 & 2.33 & 20.5 & 3.26 & 23.8 & 0.797 \\
4 & 120 & 2.46 & 21.2 & 3.37 & 22.0 & 0.785 \\
5 & 115 & 1.32 & 19.1 & 3.04 & 21.1 & 0.613 \\
6 & 119 & 2.53 & 20.0 & 3.18 & 24.6 & 0.782 \\
7 & 114 & 1.45 & 19.1 & 3.04 & 21.1 & 0.697 \\
8 & 121 & 2.30 & 21.5 & 3.42 & 20.5 & 0.754 \\
Mean & 118.6 & 2.01 & 20.1 & 3.20 & 22.95 & 0.741 \\
\pm SEM & 0.9 & 0.17 & 0.3 & 0.05 & 0.54 & 0.025 \\
Group II & & & & & & \\
9 & 119 & 1.60 & 22.0 & 3.50 & 23.0 & 0.885 \\
10 & 120 & 1.83 & 20.3 & 3.23 & 22.5 & 0.736 \\
11 & 120 & 2.40 & 21.3 & 3.39 & 24.5 & 0.942 \\
12 & 116 & 2.21 & 21.3 & 3.39 & 23.4 & 0.845 \\
13 & 121 & 1.70 & 21.2 & 3.37 & 19.1 & 0.681 \\
14 & 117 & 2.40 & 21.9 & 3.49 & 23.9 & 0.915 \\
15 & 121 & 1.59 & 21.9 & 3.49 & 19.2 & 0.735 \\
16 & 115 & 1.79 & 22.1 & 3.52 & 25.0 & 0.973 \\
Mean & 118.7 & 1.94 & $21.5 \dagger$ & $3.42 \dagger$ & 22.58 & 0.839 \\
\pm SEM & 0.8 & 0.12 & 0.2 & 0.03 & 0.80 & 0.029 \\
\hline
\end{tabular}

* GA, gestational age; wt, weight of animal; Circ, circumference; Rad, radius; $\mathrm{L}$, length; Vol, volume.

$\dagger p<0.005$ group I versus group II.

significantly $(p<0.05)$ greater airway resistance in the ventilated group for each value of flow (all Pc) and each Pc (all flows). This is graphically represented in Figure 4 by an upward shift in the line depicting the relationship between resistance and flow for group II at each Pc.

\section{DISCUSSION}

This study demonstrates that ventilation alters the compliance of premature airways and affects pressure-flow relationships by increasing airway collapsibility during compression. This increased collapsibility during compression results in increased resistance to flow.

Justification of experimental preparation. Experiments used tracheae ventilated in vivo with liquid fluorocarbon. Previous studies have examined the effect of in vitro gas ventilation on the inflation compliance of premature rabbit tracheae $(5,13)$. The possibility exists that the in vivo state retains mechanisms that influence the effect of ventilation on tracheal properties (mechanisms not present in the in vitro condition). Such mechanisms might involve the influence of an intact nervous system on tracheal smooth muscle, the influence of surrounding supportive structures (e.g. esophogus, laryngeal and pharyngeal muscles) or humoral/chemical influences associated with an intact blood flow.

A fundamental premise herein asserts the applicability of our results using liquid ventilation to those obtained in a clinical setting with various forms of gas ventilation. Bhutani and Shaffer (9) and Alsberge et al. (14) demonstrated similar alterations in tracheal dimensions and compliance when the same peak ventilatory pressures were used for both liquid and conventional gas ventilation. Furthermore, Bhutani et al. (15) have shown comparable mechanical alterations as a result of high-frequency jet ventilation. These findings suggest that the mechanical and functional alterations consequent to ventilation are a result of barotrauma. From a clinical viewpoint, both Stocks and Godfrey (16) and Bhutani et al. (7) have asserted that pressure is the common factor responsible for observed alterations in the properties of immature airways. In light of this evidence we may conclude 


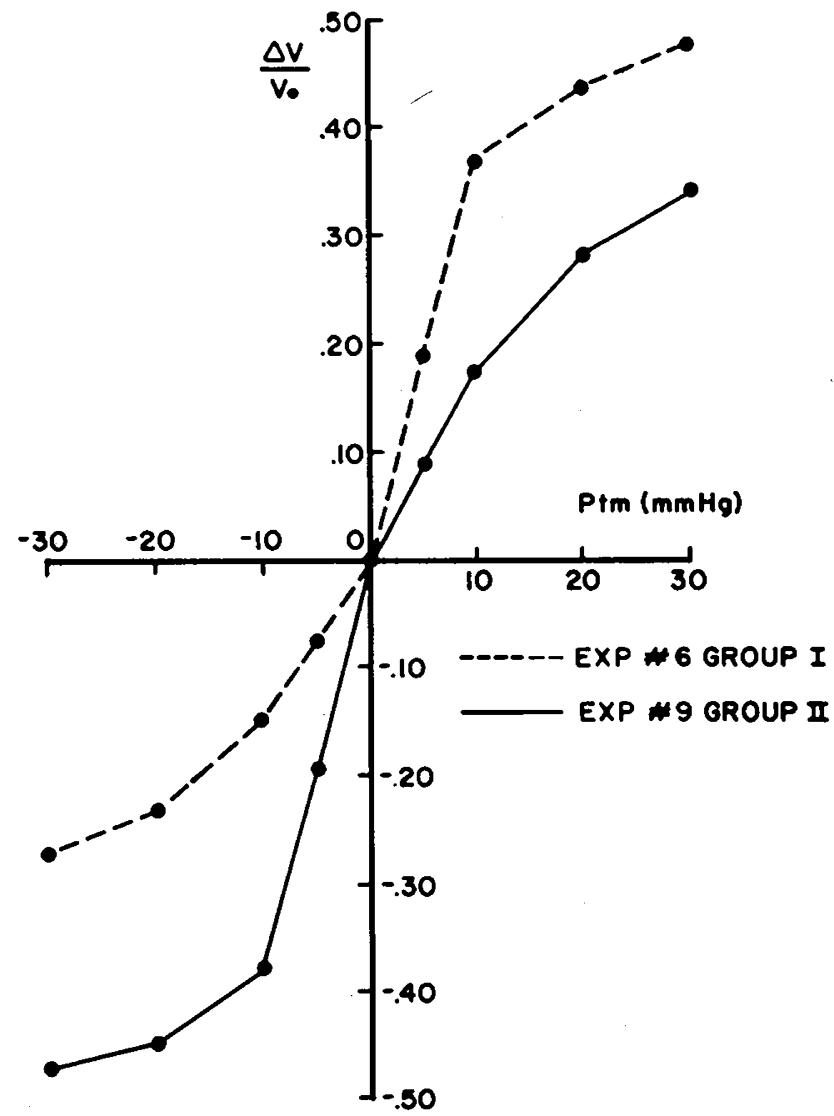

Fig. 2. Pressure $(P)$ as a function of normalized volume change $(\Delta V /$ $V o$ ) in a typical unventilated and ventilated tracheal segment.

Table 2. Inflation slopes (Si) and collapsing slopes (Sc) calculated from $P-V$ data points between $0-+10 \mathrm{~mm} \mathrm{Hg}$ and $0-$

$-10 \mathrm{~mm} \mathrm{Hg}$, respectively, for both groups I and group II tracheal segments

\begin{tabular}{ccc}
\hline Experiment & $\begin{array}{c}\mathrm{Si} \\
\left(\mathrm{mm} \mathrm{Hg}^{-1}\right)\end{array}$ & $\begin{array}{c}\mathrm{Sc} \\
\left(\mathrm{mm} \mathrm{Hg}^{-1}\right)\end{array}$ \\
\hline Group I & & \\
1 & 0.044 & 0.009 \\
2 & 0.028 & 0.025 \\
3 & 0.033 & 0.025 \\
4 & 0.048 & 0.019 \\
5 & 0.035 & 0.031 \\
6 & 0.037 & 0.015 \\
7 & 0.034 & 0.029 \\
8 & 0.029 & 0.032 \\
Mean & 0.036 & 0.023 \\
\pm SEM & 0.002 & 0.003 \\
& & \\
Group II & & \\
9 & 0.020 & 0.039 \\
10 & 0.038 & 0.035 \\
11 & 0.037 & 0.034 \\
12 & 0.018 & 0.025 \\
13 & 0.031 & 0.033 \\
14 & 0.031 & 0.027 \\
15 & 0.024 & 0.027 \\
16 & 0.024 & 0.026 \\
Mean & $0.028^{*}$ & $0.031^{*}$ \\
\pm SEM & 0.003 & 0.002 \\
\hline
\end{tabular}

${ }^{*} p<0.05$ group I versus group II.

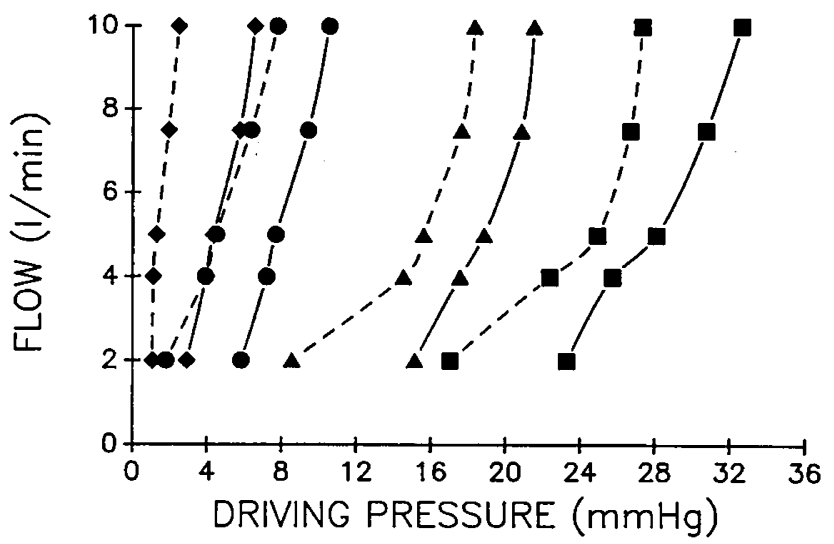

Fig. 3. Flow as a function of driving pressure at chamber pressures of $5(\diamond), 10(\bullet), 20(\Delta)$, and $30(\boldsymbol{\nabla}) \mathrm{mm} \mathrm{Hg}$ for unventilated (group I, dashed lines) and ventilated (group II, solid lines) tracheal segments. Group II required a higher driving pressure to produce the same flow at any given chamber pressure represented by a shift to the right of the pressure-flow line.

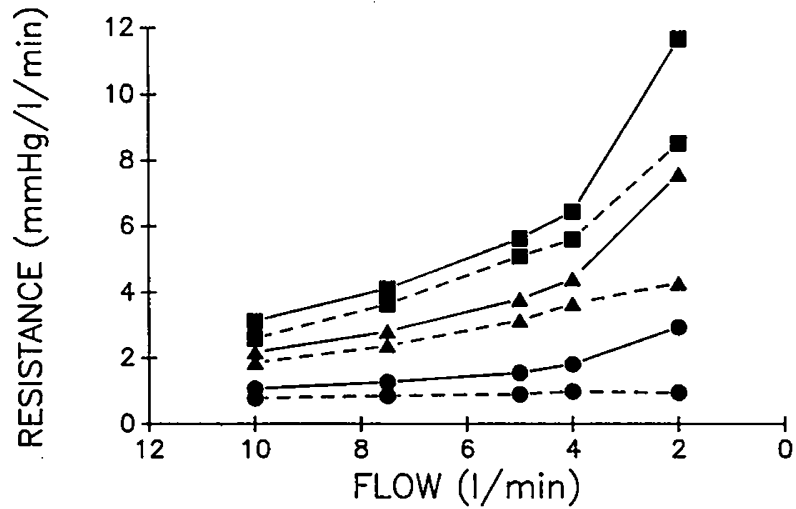

Fig. 4. Calculated tracheal resistance as a function of flow at chamber pressures of $10(\bullet), 20(\Delta)$, and $30(\boldsymbol{\nabla}) \mathrm{mm} \mathrm{Hg}$ for unventilated (group I, dashed lines) and ventilated (group II, solid lines) tracheal segments. Resistance in group II was significantly $(p<0.05)$ higher than that in group I for all values of $\dot{V}$ and Pc. (Data for values for a chamber of 5 $\mathrm{mm} \mathrm{Hg}$ were omitted for graph clarity.)

that any of the abovementioned forms of ventilation may produce similar alterations in airway mechanical properties. Liquid ventilation was chosen for our study because it is currently the only effective means to ventilate premature lambs of this age and maintain a physiological gas exchange/acid base status. Inability to maintain these parameters within physiological limits could result in histochemical damage of the airways, which may in turn alter airway structure/function. Such a disturbance may alter the airway response to ventilation. By significantly reducing the surface tension within the lung, utilization of liquid fluorocarbon also enabled ventilatory pressures to be controlled within a relatively narrow range.

It should be noted that the ventilatory procedures used herein, particularly the duration of ventilation used, represent a relatively benign stress when compared to that incurred by the airways of premature infants who are chronically gas ventilated.

As in all research that involves the use of animals, it is unclear the extent to which the data apply to humans. Previous studies have noted the similarity of tracheal morphometry (17) and mechanics (18) across species. Although we presently find no reason to suggest that results obtained from the premature human would be qualitatively different from those presented herein, future research using human tracheae is clearly indicated. 
Airway dimensions, mechanical properties. The extent of ventilation-induced deformation appears to be directly related to the magnitude of pressure and duration of ventilation, compliance of the airway, and inversely related to gestational age (5-7). An increase in the airway radius associated with ventilation, suggesting barotrauma, has been well-documented in both humans $(7,8)$ and animals of various gestational age $(5-7)$. Our results are consistent with these studies in that a significant difference between the radii of unventilated and ventilated segments was demonstrated.

Neonatal airways have been shown to be more compliant than adult airways $(12,19,20)$. Furthermore, preterm airways have been shown to be more compliant than newborn airways in the rabbit (12). Comparison of the compliance data from unventilated lamb tracheas in this study with the compliance data from newborn lamb tracheas in Koslo et al. (21) shows greater compliance in our preterm group. These results further confirm the inverse relationship between airway compliance and gestational age.

Ventilation of preterm rabbit airways has been shown to decrease the airway compliance as determined by the inflation loop of the P-V curve $(5,13)$. Our data suggest a similar decrease in this compliance in preterm lamb tracheae. However, compliance as determined by the collapsing loop of the P-V curve shows greater collapsing compliance in the ventilated trachea. Airway collapse will therefore be greater at a given negative transmural pressure after ventilation. These alterations in inflation and collapsing compliance consequent to ventilation produce a structure analogous to a firehose, in which inflation beyond the volume at zero transmural pressure is difficult, but collapse with negative transmural pressures is accomplished easily.

Pressure-flow relationships. Pressure-flow data depicted in Figure 3 show increased driving pressure associated with increased flow at a given chamber pressure. Furthermore, increased driving pressure was necessary to produce flow as chamber pressure was increased. These experimental results are consistent with theories describing pressure-flow relationships in elastic tubes (22-24), which are based on experiments using Starling resistors similar to our experimental design.

Unlike pressure-flow curves that assume laminar flow and a constant tube radius, the pressure-flow curves in Figure 3 are markedly nonlinear. The convexity of the curves occurs as a result of tracheal expansion as driving pressure was increased at a constant chamber pressure; this expansion more than offset any increase in resistance that might have been caused by flow turbulence, and the slope of the pressure-flow curve increased. When additional experiments were performed (Penn RB, Wolfson MR, Shaffer TH, unpublished observations) that included flow values of 15 and 20 liter/min, the slope of the pressure-flow curves began to decrease at these higher flows, suggesting that tracheal expansion began approaching its limit and increasing flow turbulence became the dominant resistance factor.

Figure 4 depicts airway resistance increasing with decreasing flow for both groups at all chamber pressures. This relationship implies that when chamber pressure is held constant, transmural pressure $(\mathrm{Ptm}=\mathrm{Pd}-\mathrm{Pc})$ decreases as driving pressure and flow decrease. Consequently, tracheal cross-sectional area (dependent on transmural pressure) decreases with decreasing flow, resulting in an increase in airway resistance.

Each curve in Figure 4 may be considered analogous to the relationship between resistance and flow that occurs during a forced expiration at a constant effort. Higher Pc indicates greater effort. Initially, flow is high and resistance is low due to 1) the high driving pressure associated with high lung volume and recoil pressure and 2) the relative lack of airway compression consequent to relatively positive Ptm. As expiration progresses, alveolar driving pressure diminishes, and flow decreases. Concomitantly, Ptm becomes more negative, resulting in greater airway compression and greater resistance to airflow.
Changes in tracheal compliance have been shown to alter the pressure-flow relationships of tracheae subjected to compressive pressures. Previous studies have examined the effect of tracheal smooth muscle contraction (induced by administration of cholinergic agonists) on resistance to airflow in adult canine $(2,3)$ and newborn lamb (4) tracheae. Smooth muscle contraction resulted in less compliant tracheae during both inflation and collapsing pressures. Furthermore, resistance to airflow during compression was significantly less than that of control tracheae. In our study airway resistance was significantly greater in group II compared to group I at each individual flow and each individual Pc. These results suggest that the increase in tracheal collapsing compliance as a consequence of chronic mechanical ventilation resulted in a floppy airway with greater susceptibility to dynamic compression.

Physiological significance. The tracheal volume deformation in infants who have received ventilatory support translates into acquired tracheomegaly and an increase in dead space volume $(7,8)$. This increase in dead space may explain some of the hypercapnia, acidosis, and increased work of breathing $(25,26)$ associated with extubation and weaning chronically ventilated infants from the ventilator. Furthermore, the long-term effects of mechanical ventilation on infants have been implicated in the etiology of bronchopulmonary dysplasia (22-29), and may also retard the normal growth rate of airways (16).

Expiratory efforts during forced expiration result in pleural pressures that represent high compressive forces in proximal intrathoracic airways. Dynamic compression of these airways serves to increase upper airway resistance and partially or fully offsets increases in expiratory flow that might occur as alveolar driving pressure is increased by increased effort. When increasing expiratory effort does not result in an increase in expiratory flow, flow limitation occurs.

Mead et al. (30) have described this phenomenom in terms of an EPP. During forced expiration, alveolar driving pressure is progressively dissipated until a point is reached along the airways where the intraluminal airway pressure equals the pleural pressure-the EPP. The EPP may migrate peripherally with increased effort until it become fixed, usually within the second or third generation bronchi during forced expiration in the adult human. At or around the EPP a FLS of airway exists, whose dimensions are critical in determining MEF. Whereas it is presently unclear whether alterations in airway compliance downstream from the EPP influence the magnitude of flow limitation (30), the compliance of the FLS has been shown to be inversely related to MEF and directly related to airway resistance (1). Several mathematical models have also been developed that predict MEF as a function of FLS compliance (31-33). These models have been supported by subsequent experimental observations $(1,32,33)$.

Given this analytical context, premature infants with highly compliant airways are therefore predisposed to greater airway compression and high resistance to airflow; greater airway collapse at a given transmural pressure may also cause flow limitation to occur at low efforts in the preterm, effectively reducing expiratory flow reserve. High airway compliance in more distal airways also increases the likelihood of gas trapping, which occurs as a result of complete airway collapse.

High airway resistance, flow limitation, and gas trapping all increase the work of breathing and limit the capacity of the preterm to sustain effective gas exchange and acid-base balance. By increasing the already high collapsing compliance of immature airways, mechanical ventilation may serve to exacerbate this condition, further limiting the premature infant's physiological range of breathing.

Highly compliant extrathoracic airways may also contribute to high airway resistance during inspiration. Subatmospheric pressures created during inspiration are usually insufficient to produce significant narrowing of the extrathoracic airway. However, under certain clinical conditions such as those seen in 
premature infants who sustain prolonged ventilation (increasing collapsing compliance) and exhibit high nasal resistance and/or subglottic stenosis (creating more subatmospheric extrathoracic airway pressures) the probability of extrathoracic airway narrowing is greatly increased.

In conclusion, this study demonstrates that mechanical ventilation of premature airways results in pressure-induced deformation and alterations in mechanical properties. These alterations in mechanical properties produce airways highly susceptible to dynamic compression. These finding may help to explain the flow limitation and gas trapping observed in infants who have been mechanically ventilated.

\section{REFERENCES}

1. Jones JG, Fraser RB, Nadel JA 1975 Effect of changing airway mechanics on maximum expiratory flow. J Appl Physiol 38:125-131

2. Knudson RJ, Knudson DE 1975 Effect of muscle constriction on flow-limiting collapse of isolated canine trachea. J Appl Physiol 38:125-131

3. Coburn RF, Thorton D, Art R 1972 Effect of trachealis muscle contraction on tracheal resistance to airflow. J Appl Physiol 32:397-403

4. Bhutani VK, Koslo RJ, Shaffer TH 1986 The effect of tracheal smooth muscle tone on neonatal airway collapsibility. Pediatr Res 20:492-495

5. Bhutani VK, Rubenstein SD, Shaffer TH 1981 Pressure-induced deformation in immature airways. Pediatr Res 15:829-832

6. Snyder SM, Shaffer TH, Bhutani VK 1984 Tracheal volume deformation in a developmental rabbit model. Biol Neonate 46:192-197

7. Bhutani VK, Ritchie WG, Shaffer TH 1986 Acquired tracheomegaly in very preterm neonates. Am J Dis Child 140:449-452

8. Palmer J, Schidlow B, Wolfson B, Capitanio M, Huang N 1979 Tracheomegaly. A finding in two children who survived prolonged intubation and mechanical ventilation for hyaline membrane disease. Pediatr Res 13:1282(abstr)

9. Bhutani VK, Shaffer TH 1983 Effect of liquid ventilation on preterm tracheal mechanics. Biol Neonate 44:257-263

10. Shaffer TH, Tran N, Bhutani VK, Sivieri EM 1983 Cardiopulmonary function in very preterm lambs during liquid ventilation. Pediatr Res 17:680-684

11. Panitch H, Allen J, Ryan J, Wolfson MR, Shidlow DV, Shaffer TH 1987 Length-tension relationships and force generation in ventilated and unventilated trachealis muscle from preterm lambs. Am Rev Respir Dis 135:A122

12. Bhutani VK, Rubenstein SD, Shaffer TH 1981 Pressure-volume relationships of trachea in fetal, neonatal, and adult rabbits. Respir Physiol 43:221-231

13. Bhutani VK, Shaffer TH 1981 Effect of positive pressure application on the bulk modulus of the developing rabbit trachea. Respiration 41:192-198
14. Alsberge MS, Wolfson MR, Bhutani VK, Minczak BM, Shaffer TH 1987 Ventilation induced changes in functional characteristics of immature airways. Fed Proc 46:513

15. Bhutani VK, Shaffer TH, Spitzer AR, Fox WW 1986 Effect of high frequency jet ventilation on neonatal tracheal mechanics. Pediatr Pulmonol 1:327-331

16. Stocks J, Godfrey $S 1977$ Specific airway conductance in relation to postconceptual age during infancy. J Appl Physiol 43:144-154

17. Mortola JP, Fisher JT 1980 Comparative morphology of the trachea in newborn mammals. Respir Physiol 39:297-302

18. Koslo RJ, Wolfson MR, Shaffer TH 1983 Tracheal mechanics: a comparative mammalian study. Fed Proc 42:616

19. Croteau JR, Cook CD 1961 Volume-pressure and length-tension measurements in human tracheal and bronchial segments. J Appl Physiol 16:170172

20. Burnard ED, Grattan-Smith P, Picton-Marlow CG, Grauaug A 1965 Pulmonary insufficiency in prematurity. Aust Paediatr $\mathrm{J}$ 1:12-38

21. Koslo RJ, Bhutani VK, Shaffer TH 1986 The role of tracheal smooth muscle contraction on neonatal tracheal mechanics. Pediatr Res 20:1216-1220

22. Rodbard S 1955 Flow through collapsible tubes: augmented flow produced by resistance at outlet. Circulation 11:280-290

23. Permutt S, Riley RL 1963 Hemodynamics of collapsible vessels with tone: the vascular waterfall. J Appl Physiol 18:924-932

24. Green, JF 1977 Mechanical Concepts in Cardiovascular and Pulmonary Physiology. Lea and Febiger, Philadelphia

25. Thibeault DW, Clutarid B, Auld PAM 1966 The oxygen cost of breathing in the premature infant. Pediatrics 37:954-959

26. Wolfson MR, Bhutani VK, Shaffer TH, Bowen FW 1984 Mechanics and energetics of breathing helium in infants with bronchopulmonary dysplasia. J Pediatr 104:752-757

27. Northway WH, Rosan RC, Porter DY 1967 Pulmonary disease following respirator therapy of hyaline membrane disease: bronchopulmonary dysplasia. N Engl J Med 276:357-368.

28. Bancalari E, Abdenour GE, Feller R 1979 Bronchopulmonary dysplasia: Clinical presentation. J. Pediatr 95:819-822

29. O'Brodovich HM, Mellins RB 1985 Bronchopulmonary dysplasia (state of the art). Am Rev Respir Dis 132:684-709

30. Mead J, Turner JM, Macklem PT, Little, JB 1967 Significance of the relationship between lung recoil and maximum expiratory flow. J Appl Physiol 22:95-108

31. Fry DL 1968 A preliminary lung model for simulating the aerodynamics of the bronchial tree. Comput Biomed Res 2:111-134

32. Jones JG, Fraser RB, Nadel JA 1975 Prediction of maximum expiratory flow rate from area-transmural pressure curve of compressed airway. J Appl Physiol 38:1002-1011

33. Lambert RK, Wilson TA, Hyatt RE, Rodarte JR 1982 A computational model for expiratory flow. J Appl Physiol 52:44-56 